\title{
Study of knowledge and contraception practices in low socio-economic women of Delhi
}

\author{
Divya Pandey ${ }^{*}$, Deepali Garg ${ }^{2}$, Sudha Salhan $^{1}$
}

\author{
${ }^{1}$ Department of Obstetrics \& Gynaecology, North Delhi Municipal Corporation Medical College and Hindu Rao \\ Hospital, Delhi-7, India \\ ${ }^{2}$ Department of Obstetrics \& Gynaecology, Kastoorba Hospital, North Municipal Corporation of Delhi, Delhi, India
}

Received: 30 September 2014

Accepted: 1 November 2014

\author{
*Correspondence: \\ Dr. Divya Pandey, \\ E-mail:dr_devya1@yahoo.co.in,drdevya1@gmail.com
}

Copyright: ( $)$ the author(s), publisher and licensee Medip Academy. This is an open-access article distributed under the terms of the Creative Commons Attribution Non-Commercial License, which permits unrestricted non-commercial use, distribution, and reproduction in any medium, provided the original work is properly cited.

\begin{abstract}
Background: Objective of current study was to assess the knowledge and practice of contraception among the low socio-economic women of reproductive age group in Delhi.

Methods: A cross-sectional study was done on 272 low socio-economic women attending a family planning clinic at a Delhi municipal corporation hospital, of which 106 came for Medical Termination of Pregnancy (MTP) and 166 came for family planning advice. They were interrogated through a pre-designed structured questionnaire, to evaluate their knowledge and practices towards regular contraceptive methods, Emergency Contraception (EC) and medical abortion. They were counselled about the available contraceptive methods and allowed to make choices according to their suitability.

Results: All women belonged to low socio-economic group according to the modified Kuppuswamy scale. $22.1 \%$ were illiterate. $47.8 \%$ were ignorant of contraception. $38.3 \%$ women were aware of EC. Only $24.2 \%$ knew about medical abortion. The main reasons cited for not using contraception was desire for male child (24.6\%), fear of side effects $(20 \%)$, desire for another child (20\%), opposition from family members $(15.4 \%)$, inaccessibility $(4.6 \%)$ and inconvenience and lack of privacy $(5.4 \%)$.

Conclusions: This study highlights that lack of education, knowledge and awareness led to inadequate usage of regular methods of contraception in reproductive age group women belonging to low socio-economic status. Thus only availability is not sufficient to reach optimum female health. Accessibility need to be increased by educating females and motivating couples to make adequate use of existing family planning methods and resources. In contrast the awareness for emergency contraception is more than regular methods. It mandates need to educate women that emergency contraception should not replace regular methods.
\end{abstract}

Keywords: Knowledge, Practice, Medical abortion, Emergency contraception, Contraception, Low socio-economic, Delhi.

\section{INTRODUCTION}

India, being the second most populous country in the world, with population reaching 1.21 billion and decadal growth rate of $17.64 \%$ as per the 2011 census, population control is one of the major issues to be addressed by the Indian government. The efforts on the part of the government are to control the situation by making availability and accessibility of the family planning methods. After implementing National Family Planning Program in 1951, due emphasis and importance has been laid on it in almost all successive five year plans. But despite farsightedness of Indian government, the goal has not yet been achieved. There are still miles to go to reach the total fertility rate of 2.1 as set by National Population Policy 2000. ${ }^{1}$ Contraception methods decrease the total fertility and provide proper spacing of pregnancies to reduce the maternal morbidity and mortality. ${ }^{2}$ Despite 
constant government efforts, the 'unmet need of contraception' which refers to a disparity between woman's fertility preferences and her family planning practices, still persists. $^{3}$

The present study aimed to assess the knowledge and practice of contraception methods among reproductive age, low socio-economic status women of Delhi.

\section{METHODS}

272 women of reproductive age group, belonging to lower and lower upper socio-economic class according to the Modified Kuppuswamy scale, attending the family planning clinic of a municipal corporation hospital, who came to seek family planning advice (after being referred from general gynaecology OPD for contraception counseling) and for Medical Termination of Pregnancy, over a period of two months were evaluated for their knowledge and practices towards regular contraceptive methods, emergency contraception and medical abortion with the help of a structured questionnaire. Women were then given the cafeteria choice of different contraception methods available and contraceptive method accepted by them was recorded and analysed statistically.

\section{RESULTS}

Table 1 shows the socio-demographic characteristics of the studied sample.

Table 1: Demographic characteristics of the studied sample of women.

\begin{tabular}{|lll|}
\hline $\begin{array}{l}\text { Characteristics } \\
\text { Medical termination } \\
\text { of pregnancy cases }\end{array}$ & $\begin{array}{l}\text { No. of women } \\
(\mathrm{n}=272)\end{array}$ & $\begin{array}{l}\text { Percentage } \\
(\%)\end{array}$ \\
\hline $\begin{array}{l}\text { Family planning } \\
\text { advice seekers }\end{array}$ & 166 & 39 \\
\hline Age & 61 \\
\hline Range & $20-40$ year \\
\hline Mean Age & 26.4 years \\
\hline Parity & \\
\hline 0 & 2 & 0.7 \\
\hline 1 & 20 & 7.4 \\
\hline 2 & 56 & 20.6 \\
\hline 3 & 75 & 27.6 \\
\hline 4 & 113 & 41.5 \\
\hline$>4$ & 6 & 2.2 \\
\hline Education & & \\
\hline Illiterate & 60 & 22.1 \\
\hline Primary & 186 & 68.4 \\
\hline Secondary and above & 26 & 9.5 \\
\hline Socio-economic status & 65 \\
\hline Lower & 177 & 35 \\
\hline Lower upper & 95 & \\
\hline
\end{tabular}

Of 272 women, 39\% (106) came for Medical Termination of Pregnancy (MTP) while 61\% (166) came to seek family planning advice. Mean age of the studied women was 26.4 years, $43.7 \%$ being of parity four or above. $22.1 \%$ were illiterate while $68.4 \%$ had only primary education. $65 \%$ belonged to lower while $35 \%$ belonged to upper lower socio-economic class as per the modified Kuppuswamy scale (Table 1).

From Table 2, it is seen that, while $47.8 \%$ had no knowledge of any contraceptive methods, $21.7 \%$ were using Intrauterine Contraceptive Device (IUCD) followed by Barrier contraceptive usage by $18.8 \%$. Oral contraceptive pills were used only by $4.4 \% .24 .2 \%$ were aware of Medical Abortion (MA) while only $17 \%$ had actually used it. Similarly $38.3 \%$ were aware of Emergency Contraception (EC) while $24.6 \%$ had actually used it. Of 106 women who came for MTP, 62.3\% had unplanned pregnancy, while $35.8 \%$ had failed contraception. $65 \%$ of females were unaware of noncontraceptive benefits of the various methods.

Table 2: Knowledge and practice of contraception, medical abortion and indication for medical termination of pregnancy $(n=272)$.

\begin{tabular}{|c|c|c|}
\hline Characteristics & $\begin{array}{l}\text { No. of } \\
\text { women } \\
(n=272)\end{array}$ & $\begin{array}{l}\text { Percentage } \\
(\%)\end{array}$ \\
\hline \multicolumn{3}{|l|}{ Use of contraception $(n=272)$} \\
\hline No contraception & 130 & 47.8 \\
\hline Barrier method & 51 & 18.8 \\
\hline Intra uterine contraceptive device & 59 & 21.7 \\
\hline Oral contraceptive pills & 12 & 4.4 \\
\hline Others & 20 & 7.3 \\
\hline \multicolumn{3}{|c|}{ Knowledge of medical abortion $(n=272)$} \\
\hline Heard about medical abortion & 66 & 24.2 \\
\hline Used medical abortion & 46 & 17 \\
\hline Unaware & 160 & 58.8 \\
\hline \multicolumn{3}{|c|}{ Knowledge of emergency contraception $(n=272)$} \\
\hline Heard of EC & 104 & 38.3 \\
\hline Used EC & 67 & 24.6 \\
\hline Unaware & 101 & 37.1 \\
\hline \multicolumn{3}{|c|}{ Indications of medical termination of pregnancy $(n=106)$} \\
\hline Unplanned pregnancy & 66 & 62.3 \\
\hline Failed contraception & 38 & 35.8 \\
\hline Poor maternal health & 2 & 1.9 \\
\hline \multicolumn{3}{|c|}{ Knowledge of non-contraceptive benefits } \\
\hline No knowledge & 177 & 65 \\
\hline Knowledge present & 95 & 35 \\
\hline
\end{tabular}

Table 3 shows, while desire for male child was most common $(24.6 \%)$ reason for not using contraception, fear of side-effects and desire for further conception was seen in $20 \%$ each. $15.4 \%$ cited family/spouse opposition as a cause. $4.6 \%$ accounted for inaccessibility to family planning services while $5.4 \%$ said inconvenience was the main reason. 
Table 3: Reasons for not using contraception.

\begin{tabular}{|lll|}
\hline Reason & $\begin{array}{l}\text { No. of women } \\
(\mathbf{n = 1 3 0 )}\end{array}$ & $\begin{array}{l}\text { Percentage } \\
(\%)\end{array}$ \\
\hline Worried of side effects & 26 & 20 \\
\hline $\begin{array}{l}\text { Opposition from family } \\
\text { members/spouse }\end{array}$ & 20 & 15.4 \\
\hline Wanted male child & 32 & 24.6 \\
\hline Wanted conception & 26 & 20 \\
\hline $\begin{array}{l}\text { Inconvenience/lack of } \\
\text { privacy }\end{array}$ & 7 & 5.4 \\
\hline $\begin{array}{l}\text { No access to family } \\
\text { planning services }\end{array}$ & 6 & 4.6 \\
\hline
\end{tabular}

Post counselling, (Table 4) most common form of contraceptive adopted by group 1 was IUCD $(56.7 \%)$ followed by permanent method of sterilization (40.6\%). While those who came for family planning advice, maximum (41.6\%) inclined for barrier contraceptive followed by IUCD (31.2\%). Oral Contraceptive Pills (OCPs) and permanent method of sterilization were adopted by $10.2 \%$ and $9.6 \%$ respectively.

Table 3: Contraception form accepted after counseling.

\begin{tabular}{|c|c|c|}
\hline Characteristics & $\begin{array}{l}\text { No. of } \\
\text { women } \\
(n=272)\end{array}$ & $\begin{array}{l}\text { Percentage } \\
\%\end{array}$ \\
\hline \multicolumn{3}{|c|}{$\begin{array}{l}\text { Group } 1 \text { [Medical termination of pregnancy group } \\
(n=106)]\end{array}$} \\
\hline Oral contraceptive pills & 2 & 1.9 \\
\hline Intra uterine contraceptive devices & 59 & 56.7 \\
\hline Bilateral tubal ligation & 43 & 40.6 \\
\hline Barrier method & 2 & 1.9 \\
\hline \multicolumn{3}{|l|}{ Others } \\
\hline \multicolumn{3}{|c|}{ Group 2 [Family planning group $(n=166)]$} \\
\hline Oral contraceptive pills & 17 & 10.2 \\
\hline Intra-uterine contraceptive devices & 53 & 31.2 \\
\hline Bilateral tubal ligation & 16 & 9.6 \\
\hline Barrier method & 69 & 41.6 \\
\hline Change of IUCD & 11 & 6.6 \\
\hline
\end{tabular}

\section{DISCUSSION}

The mean age of patient in our sample was 26.4 years. Most of them were of high parity, probably because more the number of children, more was the likelihood of her wanting contraception. Similar result was also reflected by Imasiku et al. where the average parity of women seeking contraception was $6.7 .^{4}$ All patients in our study belonged to low socio-economic status, $22.1 \%$ being illiterate and $68.4 \%$ with only primary education. This was similar to the study sample of Tuladhar et al. ${ }^{5}$

Inspite of availability of safe and effective contraception methods only half $(52.2 \%)$ females were aware of the available contraceptive methods. This lack of awareness was probably due to low literacy status and low socio- economic status. This was in contrast to $94.2 \%$ awareness according to Renjhen $\mathrm{P}$ et al., 94\% according to Zafar et al., $95.8 \%$ as per a Korean study and even upto $100 \%$ according to Srivastava et al. ${ }^{6-9}$ This difference was due to higher socio-economic and literacy status of these populations.

However our result was similar to the study in Nigeria which also showed low awareness of $54.3 \%$ and that by Srivastava et al., where it was only $17 \% .^{10,11}$

Women's low literacy status is one of the factors affecting the knowledge regarding contraception. This was also reflected in the study by Srivastava et al and Ali et al. ${ }^{11,12}$ Another study conducted in Bombay also concluded that education was the main variable and main influencing factor in the decisions regarding family size and contraceptive awareness. ${ }^{13}$ Similarly Gautam et al. in their study concluded that raising education level will help in improving acceptance of contraceptive devices. ${ }^{14}$ Thus low literacy level among the women stresses the need for stressing upon female education as a key factor to combat over-population and to encourage the contraceptive use.

Educating girls and young women is particularly important for their empowerment, health and the wellbeing of their families and communities in turn. It helps women to become critical consumers of information, enabling them of distinguishing between correct and incorrect facts.

In 1975, Tietze and Bongaarts observed that "levels of fertility required for population stabilization cannot be easily obtained without induced abortion". ${ }^{15}$ When safe abortion is accessible in a country, the Total Fertility Rate (TFR) is likely to be one child lower than if abortion is not accessible. ${ }^{16}$ Similarly emergency contraception provides a safe and effective means of post coital contraception and has been estimated to prevent atleast $75 \%$ of pregnancies expected from unprotected sexual intercourse. ${ }^{17}$ In contrast to low awareness of regular contraception in the females belonging to the low socioeconomic status and low literacy level, awareness rates for MA and EC in this class, were $24.2 \%$ and $38.3 \%$ respectively. This was due to availability of these drugs as 'over the counter drugs' and role of mass media in promoting them. The potential benefits of EC are most evident in Sub Saharan Africa like Nigeria, where regular contraceptive prevalence is low and unwanted pregnancies with unsafe abortions are rampant. ${ }^{18}$ Very few family planning programs have incorporated EC as part of their routine services. ${ }^{19}$ To avoid misuse, medically unsupervised usage and wrong dosing (as these are available as "over the counter drug") and hence increased failure rates, the women should be familiarized about the proper usage regime and failure rate of EC and MA pills, when they come for routine contraceptive advice. This knowledge will enhance the proper usage and thus help in more participation with increase in the success rates. The population of women seeking 
emergency contraception or medical abortion is most receptive for further contraceptive use and should be another 'target group' for family planning counselling.

One fourth $(24.6 \%)$ of studied population did not use contraception in the desire of male child. This shows male child preference still prevailing the Indian society especially in low socio-economic class. $20 \%$ of women in our study refrained from using contraception due to fear of side effects. Fear of side effects and misconceptions is wide spread and has been the most important explanation for non-use of contraception. ${ }^{20-24}$ In many cultures and contraceptives are perceived as more dangerous than childbirth. $^{24}$ Many Africans believe that pills and injectables lead to infertility. Even the religious rules and value systems often limit the mobility and decision making capacities of women. ${ }^{25}$ Opposition from the family members/spouse was seen in $15.4 \%$. This is really sad for country like India where the male dominance still prevails which forbids the women from her independent decision making. Considering this, husband and mother in law should be aimed as 'target groups' for contraception counselling for better adoptability of a method. Low income women have fewer opportunities for getting necessary information, so easier access to reproductive health education should be priority. Similarly low income females also don't seek medical care owing to their limited income. So government should make strategies of making family planning services more accessible and affordable.

Thus many of the barriers to family planning are there which remain ignored by government as well as private organizations, viz. shortfalls and breaks in commodity supplies, arbitrary medical rules and restrictions before contraception can be used, unaffordable prices, laws restricting the provision of safe abortion as well as widespread misinformation about contraception. ${ }^{25}$ The knowledge of non-contraceptive knowledge of noncontraceptive benefits was present in one-third of the studied sample. Making them aware of these potential benefits probably will make them more acceptable.

$62.3 \%$ went for MTP for unplanned pregnancy which was due to lack of use of regular contraceptive methods. This reflects the impulsive nature of human sexual behavior. Although government of India is trying to meet the unmet needs of contraception, but many women still end up in unwanted pregnancy and request for MTP. Despite availability of government/government approved MTP centers, owing to their low literacy status reach unqualified practitioners for unsafe abortion and land up in septic abortion which is still a major cause of maternal mortality and morbidity in India.

In our study most of the MTP seeking women went for IUCD $(56.7 \%)$ followed closely by sterilization $(40.6 \%)$. This behavior was probably as a result of the discomfort of surgery, which made them to go for permanent or at least a long lasting method. After completing family, females tend to choose a more permanent form of contraception. Younger women with incomplete females tend to choose temporary methods. However in family planning seeking group, use of barrier methods (male condom) was maximum (41.6\%) signifies the influence of male dominance in decision making of females. But high failure rate associated with barrier usage should be emphasized and use of other methods with low failure rates should be stressed on the women. The responsibility on the part of government and private medical organisations is to make availability and accessibility to the regular contraception methods by clearing all doubts regarding side effects, allaying anxiety and misconceptions, empowering women by increasing the education level, highlight the contraceptive and noncontraceptive benefits. All post-partum women must receive adequate family planning advices during their postnatal follow-up visits.

However this study had several limitations. The sample size was small, moreover since most of the women came alone, so male partners and family members influencing the decision making of females especially mother-in-laws were not directly involved in the study. As they have major influence on adoption of a particular contraception, in country like India, are the major target groups who need to be focused on and involved in the study. Inspite of every possible effort to obtain the correct information, possibility of misreporting cannot be ruled out keeping in view the low literacy level of the females in study. Further research is needed on reasons of premature discontinuation of a specific method. In order to bridge the gap between knowledge and practice of contraception, there must be regular uninterrupted availability and supply of contraceptive methods and good quality of family planning services both at government and private sectors. Alternative methods of contraception must be informed and offered so as to improve the rate of contraception utilization

Its high time for our policy makers to adopt the "opportunity model" given by Campbell MM et al. which says 'whenever women have access to a range of contraceptive methods with correct information backed up by safe abortion, fertility will fall'. ${ }^{25}$

\section{CONCLUSIONS}

There still remains a gap between knowledge and practice of contraception especially in low socio-economic class which needs to be bridged. Family planning counseling needs to be universally included into routine antenatal and postnatal clinics. It should include non-contraceptive health benefits messages too. Moreover emphasis should be laid on promoting female education and thus women empowerment to enable them of independent decisionmaking especially in issues pertaining to their health. Role of mass media like T.V. should be utilized efficiently in spreading awareness among the lower socio-economic and lower literate strata of society. Besides, the government and private medical sectors 
should play important role in allaying and dispelling the prevailing misinformation and misconception, making methods available, accessible and affordable. Emergency contraception and medical abortion should be made part of family planning programs and should be administered under medical supervision to enhance their success rates.

Funding: No funding sources

Conflict of interest: None declared

Ethical approval: Not required

\section{REFERENCES}

1. Registrar General and Census Commissioner India. Government of India. Sample Registration System, 2007. Available at: http://www.censusindia.gov.in/.

2. Dabral S, Malik SL. Demographic study of Gujjars of Delhi: UV. KAP of family planning. J Hum Ecol 2004;16:231-7.

3. Nnada AR. Understanding the unmet needs for contraception and challenges for meeting the same in India. Chatterjee A, Mahapatra PD, eds. Obstetrics and Gynaecology Highlights: an Evidence based Review. 1st ed. Kolkata: Modern Graphica; 2006: 346-354.

4. Imasiku EN, Odimegwu CO, Adedini SA, Ononokpono DN. Variations in unmet need for contraception in Zambia: does ethnicity play a role? J Biosoc Sci. 2013 Jul;19:1-22.

5. Tuladhar H, Marahatta R. Awareness and practice of family planning methods in women attending gynaecological OPD at Nepal medical college teaching hospital. Nepal Med Coll J. 2008;10(3):184-91.

6. Renjhen P, Gupta S, Das, Barua A, Shipra J, Khati B. A study of knowledge, attitude and practice of family planning among the women of reproductive age group in Sikkim. J Obstet Gynaecol India. 2008;58:63-7.

7. Zafar MI, Ford N, Ankomah A. Significance of beliefs and values predicting fertility and contraceptive behavior in Pakistan. J Biol Soc Sci. 1995;27:301-18.

8. Planned Parenthood Federation of Korea (PPFK) Yonsei UniversityBenchmark Survey report on community based distribution of contraceptives in Korea. In: PPFK, eds. A Survey. Korea: Center for Population and Family Planning; 1976: 51-64.

9. Riley AP, Stewer MK, Chakarborty J. Programme and method related determinants of the first DMPs. Use duration in rural Bangladesh. Stud Fam Plann. 1994;25:255-67.

10. Sylvia Osayi Osemwenkha. Gender issues in contraceptive use among educated women in Edo state. Niger Afr Health Sci. 2004;4:40-9.

11. Srivastava R, Srivastava DK, Jina R, Srivastava K, Sharma N, Sana S. Contraceptive knowledge, attitude and practice survey. J Obstet Gynaecol India. 2005;55:546-50.

12. Ali S, White FMM. Family planning practices among currently married women in Khairpur district, Sindh, Pakistan. J Coll Physicians Surg Pak. 2005;15:422-5.

13. Kanoja JK, Nirbharvane NC. Dynamics of contraceptive practice among urban Indian women. Nat'l Med J India. 1996;9:109-12.

14. Gautam AC, Seth PK. Appraisal of the knowledge, attitude and practices (KAP) of family control devices among rural Rajputs and scheduled caste of Hatwar area of Bilaspur district, Himachal Pradesh. Anthropologist. 2001;4:289-92.

15. Tietze C, Bongaarts J. Fertility rates and abortion rates: simulations of family limitations. Stud Fam Plann. 1975;6:114-20.

16. Campbell M, Bedford K. The theoretical and political framing of the population factor in development. Philos Trans R Soc Lon B Biol Sci. 2009;364:3101-13.

17. Trussell J, Rodriguez G, Ellersttson C. New estimates of the effectiveness of the Yuzpe regimen of emergency contraception. Contraception. 1998;57:363-9.

18. Okonofua FE, Odimegwu C, Ajabor H, Daru PH, Johnson A. Assessing the prevalence and determinants of unwanted pregnancy in Nigeria. Stud Fam Plann. 1999;30:67-77.

19. Von Look PF, Von Hertzen H. Emergency contraception. Br Med Bull. 1993;49:158-70.

20. Stash S. Explanations of unmet need for contraception in Chitwan, Nepal. Stud Fam Plann. 1999;30:267-87.

21. Yinger NV. Unmet need for family planning: reflecting women's perceptions. In: Yinger NV, eds. A Report. Washington, DC: International Centre for Research on women; 1998.

22. Hashmi SS, Alam K, Sheraz A. Non user and unmet need for contraception. In: Hashmi SS, Alam K, Sheraz A, eds. A Report. Islamabad, Pakistan: National Institute of Population Studies; 1993.

23. Casterline JB, Sinding SW. Unmet need for family planning in developing countries and implications for population policy. Popul Dev Rev. 2000;26:691-723.

24. Grubb GS. Women's perceptions of the safety of the pill: a survey in 8 developing countries. J Biosoc Sci. 1987;19:313-21.

25. Campbell MM, Prata N. Dola, Dotts Malcolm. The impact of freedom on fertility decline. J Fam Plann Reprod Health Care. 2013;39:44-50.

DOI: $10.5455 / 2320-1770 . i j r \operatorname{cog} 20141229$

Cite this article as: Pandey D, Garg D, Salhan S. Study of knowledge and contraception practices in low socio-economic women of Delhi. Int J Reprod Contracept Obstet Gynecol 2014;3:1022-6. 